\title{
COMUNICAÇÕES
}

\section{INFECÇÃO NATURAL DE TRIATOMÍNEOS DO ESPÍRITO SANTO POR FLAGELADOS MORFOLOGICAMENTE SEMELHANTES AO TRYPANOSOMA CRUZI}

\section{Paulo Augusto Sessa e Valquiria Rocha Daher Carias}

O fato de ser o Triatoma vitticeps o triatomineo mais freqüentemente capturado em domicilios e anexos, no Estado, quase sempre no estádio adulto,já havia sido assinalado por Santos e cols 6 e por Silveira e cols ${ }^{8}$. De hábitos primariamente silvestres nas áreas de ocorrência, foi pela primeira vez encontrado colonizando o domicilio em nosso meio por Santos e cols $^{6}$ no Municipio de Alfredo Chaves. Mais tarde Silveira e cols ${ }^{8}$ detectaram essa colonização em mais sete municipios, sendo em maior número em $\mathrm{Ca}$ choeiro do Itapemirim e Guarapari. Recentemente um outro caso de domiciliação ocorreu em Cariacica, constatado pela Superintendência de Campanhas de Saúde Pública do Ministério da Saúde - Diretoria Regional do Espirito Santo (Tabela 1).
A infecção natural desses insetos por flagelados morfologicamente semelhantes ao Trypanosoma cruzi foi demonstrada por Santos e cols ${ }^{6}$ que obtiveram um percentual de positividade de $4 \%$, por Barros e cols ${ }^{1}$ que encontraram positiva a maioria dos barbeiros examinados e por Silveira e cols ${ }^{8}$ que registraram $25,2 \%$ de positivos.

No periodo de outubro de 1979 a maio de 1984 recebemos para exame, na Disciplina de Parasitologia da Universidade Federal do Espirito Santo, 140 exemplares de triatomineos, capturados nos domicílios ou anexos, procedentes de vários municipios do Estado (Tabela 1). As espécies identificadas foram $T$. vitticeps, Panstrongylus megistus e $P$. geniculatus

Tabela 1 -Distribuição, por municipio de procedência, das espécies de triatomíneos e respectivos estadios evolutivos recebidos para exame pela Disciplina de Parasitologia da Universidade Federal do Espirito Santo no periodo de outuón de 1979 a maio de 1984

\begin{tabular}{|c|c|c|c|c|c|c|}
\hline & \multicolumn{3}{|c|}{ Espécies } & \multicolumn{2}{|c|}{ Estádio Evolutivo } & \multirow[t]{2}{*}{ Total } \\
\hline & $\begin{array}{l}\text { Triatoma } \\
\text { vitticeps }\end{array}$ & $\begin{array}{c}\text { Panstrong!lus } \\
\text { megistus }\end{array}$ & $\begin{array}{c}\text { Panstrongylus } \\
\text { geniculatus }\end{array}$ & Adulto & $\operatorname{Ninfa} *$ & \\
\hline Alegre & 4 & - & 3 & 7 & - & 7 \\
\hline Alfredo Chaves & 6 & - & - & 5 & 1 & 6 \\
\hline Anchieta & 7 & 1 & 1 & 9 & - & 9 \\
\hline Aracruz & 1 & - & - & 1 & - & 1 \\
\hline Cachoeiro do ltapemirim & 1 & - & - & 1 & - & 1 \\
\hline Cariacica & 22 & 1 & - & 7 & $16^{* *}$ & 23 \\
\hline Castelo & 1 & - & - & 1 & - & $\mathbf{1}$ \\
\hline Conceiçảo do Castelo & 11 & 4 & - & 14 & 1 & 15 \\
\hline Domingos Martins & 12 & 2 & - & 14 & - & 14 \\
\hline Ecoporanga & 1 & - & - & 1 & - & 1 \\
\hline Guarapari & 6 & 1 & - & 7 & - & 7 \\
\hline Iconha & 10 & - & - & 7 & $3 * *$ & 10 \\
\hline Linhares & 2 & - & - & 2 & - & 2 \\
\hline Rio Novo do Sul & 1 & - & - & I & - & 1 \\
\hline Santa Lcopoldina & 5 & - & - & 5 & - & 5 \\
\hline Santa Tereza & 4 & - & - & 4 & - & 4 \\
\hline Vaina & 23 & 3 & 3 & 28 & 1 & 29 \\
\hline Vila Velha & 3 & - & - & 3 & - & 3 \\
\hline Vitória & 1 & 一 & - & 1 & - & 1 \\
\hline Total & 121,00 & 12.00 & 7,00 & 118,00 & 22,00 & 140,00 \\
\hline$\%$ & 86,42 & 8,57 & 5,00 & 84,28 & 15,71 & 100,00 \\
\hline
\end{tabular}

* Todas pertencentes à espécie Triatoma vitticeps.

* Material coletado pela Superintendencia de Campanhas de Saúde Pública do Ministério da Saude - D.R. do Espirito Santo.

Trabalho realizado na Disciplina de Parasitologia do Departamento de Patologia do Centro Biomédico - UFES.

Endereço para correspondência: Rua Pinheiro Júnior 183 Santo António 29000 Vitória. Espirito Santo.

Recebido para publicação em $3 / 7 / 84$.
(Tabela 1), havendo predominio de fêmeas (78 exemplares).

Dos $102(72,85 \%)$ que chegaram vivos ou com morte recente $(85 T$. vitticeps, $10 P$. megistus e $7 P$. 
geniculatus) permitindo o exame do conteúdo intestinal, $64(62,74 \%)$ foram positivos para flagelados morfologicamente semelhantes ao $T$. cruzi, sendo 55 T. vitticeps $(64,70 \%), 6$ P. megistus $(60,00 \%)$ e $3 P$. geniculatus $(42,85 \%)$. Em nosso material não encontramos ninfas positivas. As pessoas suspeitas de terem sido picadas por esses hemipteros foram submetidas à reação de imunofluorescência indireta para doença de Chagas e os resultados foram sempre negativos.

De um exemplar adulto de $T$. vitticeps proveniente da localidade de Biriricas, municipio de Viana, isolamos, por inoculação em camundongos jovens, uma cepa caracterizada como de $T$. cruzi por Gomes e cols ${ }^{2} 3$.

Este alto percentual de positividade por nós encontrado em oposição aos poucos casos de doença de Chagas autóctones conhecidos no Estado, descritos por Pinto e cols ${ }^{5}$, Santos e cols ${ }^{7}$, Barros e cols ${ }^{1}$, Peçanha e cols ${ }^{4}$, pemite-nos concluir que esta doença permanece em baixos níveis endêmicos pelo fato de não ter ocorrido a completa domiciliação da espécie de triatomineo predominante em nossa região, $o T$. vitticeps.

\section{REFERÊNCIAS BIBLIOGRÁFICAS}

1. Barros GC, Mayrink W, Salgado AA, Barros RCG, Sessa PA. Contribuição para o conhecimento da doença de Chagas autóctone no Estado do Espirito Santo. Revista do Instituto de Medicina Tropical de São Paulo 17: 319-329, 1975.

2. Gomes NGL, Pereira FEL. Development of Trypanosoma cruz $i$ infection in mice chronically intoxicated with ethanol. In: Resumos de Comunicações da X Reunião Anual de Pesquisa Básica em Doença de Chagas, Caxambu-MG, p. 3.33, 1983.

3. Gomes NGL, Pereira FEL, Sessa PA. A quantitative study of the occurrence of mast cells in the skeletal muscle of mice infected with Trypanosoma cruzi. In: Resumos de Comunicações da X Reunião Anual de Pesquisa Básica em doença de Chagas, Caxambu-MG, p. 3.33, 1983.

4. Peçanha PM, Sessa PA, Silva FJD, Pereirs RS Almeida IM. Doença de Chagas - Apresentação de Três Casos Autóctones do Estado do Espirito Santo. In: Resumos do XIX Congresso da Sociedade Brasileira de Medicina Tropical, Rio de Janeiro-RJ, 1983.

5. Pinto AFS, Santos UM, Murad V, Pereira FEL, Zaganelli FL, Almeida AZ. Doença de Chagas no Estado do Espirito Santo. V - Primeiro caso de Chagas diagnosticado no município de Alfredo Chaves, Espirito Santo. Revista da Sociedade Brasileira de Medicina Tropical 3:53, 1969.

6. Santos UM, Pinto AFS, Almeida AZ, Zaganelli FL, Carrancho PV, Neto AN. Doença de Chagas no Estado do Espírito Santo - III - Vetores do tripanossoma. Revista da Sociedade Brasileira de Medicina Tropical 3:51-52, 1969.

7. Santos UM, Murad V, Chapadeiro E, Pereira FEL. Doença de Chagas do Estado do Espírito Santo - IV. Primeiro caso diagnosticado do município de Rio Novo do Sul. Revista da Sociedade Brasileira de Medicina Tropical, 3:52-53, 1969.

8. Silveira AC, Alencar TA, Máximo MHC. Sobre o Triatoma vitticeps Stal, 1859, no Estado do Espírito Santo, Brasil. Resumos de Comunicaçōes da X Reunião Anual de Pesquisa Básica em Doença de Chagas, Caxambu-MG, p. 5.8, 1983. 